\title{
Comparison of Primary Tumor SUVmax Between Small Cell Lung Cancer and Non-Small Cell Lung Cancer
}

\author{
Huynh Quang Huy* \\ Radiology Department, Pham Ngoc Thach University of Medicine, Vietnam
}

Received date: November 17, 2018; Published date: January 09, 2019

*Corresponding author: Huynh Quang Huy, Radiology Department, Pham Ngoc Thach University of Medicine, 2 Duong Quang Trung, District 10, Ho Chi Minh city, Vietnam

\begin{abstract}
Objective: The objective of the present study is to compare of primary tumor SUVmax between small cell lung cancer and non-small cell lung cancer.

Methods: Patients with lung cancer who underwent 18F-FDG PET-CT scans before the treatment were included in the study at Bach Mai hospital of Vietnam, from November 2015 to May 2018. The primary tumor SUVmax was calculated; the tumor size was measured; the T-N-M status was determined mainly by FDG PET-CT imaging according to the 8th Edition of the TNM Classification for Lung Cancer were recorded. A comparison of primary tumor SUVmax between SCLC and NSCLC was made using Mann Whitney U test.

Results: 519 cases ( 40 SCLC and 319 NSCLC) were analyzed. The primary tumor SUVmax of NSCLC is significantly greater than that of SCLC $(10.96 \pm 5.42 \mathrm{~cm}$ vs $8.09 \pm 3.99$, respectively, $\mathrm{p}=0.001)$. ROC area under the curve of primary tumor SUVmax for NSCLC involvement was 0.795 (95\% CI: 0.750-0.836), p $<0.0001$. An optimal cut-off value was identified as 8.39 by ROC curve, the sensitivity and specificity were $94 \%$ and $60 \%$, respectively. There was a moderate correlation between SUVmax and tumor size $(r=0.542, p<0.001)$ in NSCLC but not significant in SCLC ( $\mathrm{r}=0.279, \mathrm{p}=0.081)$. There was a moderate between SUVmax and TNM overall stage in NSCLC ( $\mathrm{r}=0.513, \mathrm{p}=0.01)$ but not significant in SCLC $(r=0.145, p=0.173)$.
\end{abstract}

Conclusion: PET-CT could contribute to the differential diagnosis of NSCLC with SCLC with high sensitivity but low specificity. In addition, SCLC is more aggressive than NSCLC, presenting with a rapid doubling time and higher propensity for widespread metastatic disease.

Keywords: Maximum standard uptake value (Suvmax); Primary tumor; Small cell lung cancer (SCLC); Non-small cell lung cancer (NSCLC)

Abbrevations: Suvmax: Maximum Standard Uptake Value; NSCLC: Non Small Cell Lung Cancer; SCLC: Small Cell Lung Cancer; PET-CT: Positron Emission Tomography-Computed Tomography; FDG: Fluorodeoxyglucose

\section{Introduction}

Lung cancer is the leading cause of death due to cancer around the world, with 1.59 million deaths per year [1]. In spite of the progress achieved in treating these patients, survival after 5 years is still poor, with approximately $15 \%-16 \%$ [2-4]. Tobacco is the main risk factor for lung cancer, increasing the likelihood of suffering this type of cancer 10 times more than a person who has not been exposed to it. Other conditions associated to a greater risk of lung cancer are idiopathic pulmonary fibrosis and exposcarcinogens such as asbestos [5,6]. Non-small cell lung cancer (NSCLC), which is the predominant histology (seen in 85$90 \%$ of all cases of lung cancer), encompasses three subtypes: squamous cell carcinoma, adenocarcinoma, and large cell carcinoma. The remaining $10-15 \%$ of cases are small cell lung cancer (SCLC) [7].
The assessment of patients with suspected lung cancer has routinely included morphological imaging evaluation, with either chest X-rays or CT of the thorax. More recently, the emergence of combined PET/CT imaging has greatly aided the investigation of lung cancer by allowing even better delineation of areas with increased tracer uptake. This modality has helped radiologists avoid the technical difficulties that arose from the independent combination of PET and CT examinations, which resulted in substantial artifacts. In addition, PET/CT has been shown to be an accurate tool for the work-up of solitary pulmonary nodules (SPNs) and for lung cancer staging-by improving the detection of metastatic disease, guiding therapy, and allowing clinical outcomes to be predicted $[8,9]$. 
18F-FDG PET has been reported to be useful in characterizing solitary pulmonary nodules [10], improving lung cancer staging [11], guiding therapy, monitoring treatment response [12] and predicting outcome [13]. The role of 18F-fluorothymidine (18F-FLT), an indirect marker of cells proliferation, has also been suggested for NSCLC and SCLC patients evaluation.For patients with lung carcinoma, the accurate determination of tumor type significantly influences treatment decision making. In general, SCLC is much more responsive to chemotherapy and consequently this comprises the mainstay of treatment. This is in contrast to NSCLC, which includes adenocarcinomas, squamous cell carcinomas, and large cell undifferentiated carcinomas of the lung. Therefore, this study sought to compare of primary tumor SUVmax between small cell lung cancer and non-small cell lung cancer.

\section{Methods}

\section{Clinical Data}

We retrospectively analyzed the 18F-FDG PET-CT findings of 359 newly diagnosed lung cancer patients (40 SCLC and 319 NSCLC), between December 2015 and October 2018. There were 257 (71.6\%) males, and 102 (28.4\%) females. All patients were defined by histological or cytological evidences. The patients were referred to Bach Mai nuclear medicine and oncology center for initial staging with PET-CT scan before treatment. Histological diagnosis of the tumors was based on the criteria of the 2015 World Health Organization [14] and the tumor-node metastasis (TNM) stage was determined according to the 8th lung cancer TNM classification of International Association for the Study of Lung Cancer.

\section{FDG PET-CT Imaging}

18F-FDG PET-CT scans were performed with a wholebody PET-CT scanner. All patients had been fasting for at least 6 hours before PET imaging, and serum glucose levels were measured to ensure that the results were $180 \mathrm{mg} / \mathrm{dl}$. All patients had a glucose level below $180 \mathrm{mg} / \mathrm{dl}$ and were injected intravenously Results

Table 1: Characteristics of the SCLC and NSCLC.

\begin{tabular}{|c|c|c|c|c|}
\hline \multicolumn{2}{|c|}{ Characteristics } & $\operatorname{SCLC}(n=40)$ & NSCLC $(n=319)$ & P value \\
\hline \multirow{2}{*}{ Age } & $<61$ & $15(37.5 \%)$ & $156(48.9 \%)$ & \multirow{2}{*}{0.173} \\
\hline & $\geq 61$ & $25(62.5 \%)$ & $163(51.1 \%)$ & \\
\hline \multirow{2}{*}{ Sex } & Male & $36(90.0 \%)$ & $211(69.3 \%)$ & \multirow{2}{*}{0.006} \\
\hline & Female & $4(10.0 \%)$ & $98(30.7 \% \%)$ & \\
\hline \multirow{3}{*}{ Tumor size } & $\leq 3 \mathrm{~cm}$ & $5(12.5 \%)$ & $88(27.6 \% \%)$ & \multirow{3}{*}{0.006} \\
\hline & $>3 \leq 5 \mathrm{~cm}$ & $10(25.0 \%)$ & $114(35.7 \%)$ & \\
\hline & $>5 \mathrm{~cm}$ & $25(62.5 \%)$ & $117(36.7 \%)$ & \\
\hline \multirow{5}{*}{ Tumor location } & Left upper lobe & $17(42.5 \%)$ & $100(31.3 \%)$ & \multirow{5}{*}{0.052} \\
\hline & Left lower lobe & $3(7.5 \%)$ & $47(14.7 \%)$ & \\
\hline & Right upper lobe & $4(10.0 \%)$ & $71(22.3 \%)$ & \\
\hline & Right middle lobe & $12(30.0 \%)$ & $53(16.6 \%)$ & \\
\hline & Right lower lobe & $4(10.0 \%)$ & $48(15.0 \%)$ & \\
\hline
\end{tabular}

with $0.15-0.20 \mathrm{mCi} / \mathrm{kg}$ (7-12mCi) FDG. At 45-60 min after the injection, data were acquired from the vertex to the upper thigh. Immediately after CT, a PET scan (PET/CT Biograph True Point - Siemens, Germany) was performed for about $25 \mathrm{~min}$, with seven to eight bed positions and $3 \mathrm{~min} /$ position. PET images were reconstructed iteratively with $\mathrm{CT}$ data for attenuation correction, using an inline integrated Siemens Esoft Workstation system. Computerized tomography integrated positron emission tomography fusion images in transaxial, sagittal, and coronal planes were evaluated visually, and the SUVmax of lesions was obtained from transaxial images.

\section{Imaging Analysis}

The PET-CT images were reviewed using the automatic PETCT fusion software on the workstation. A volumetric region-ofinterest (ROI) around the outline of primary tumor in the SCLC was placed on the axial PET images using the semi-automatic software. A threshold of $40 \%$ of the maximum signal intensity was selected to delineate ROI. Then SUVmax, SUVmean and tumor volume (TV) were automatically calculated by the PET-CT fusion software and these values were recorded from the workstation. Both radiologists who conducted the measurements together were blinded to the clinical details.

\section{Statistical Analysis}

Statistical analysis was done using SPSS 22.0 (Chicago, Illinois, USA). The mean of the measurement data was expressed as mean \pm standard deviation (mean \pm S.D). The differences of tumor SUVmax in independent groups (SCLC and NSCLC) were compared using Mann Whitney U test. An evaluation was made of the linear relationship between tumor size, tumor stage, nodal stage, and overall stages of the patients and their SUVmax using Spearman's correlation. Receiver operating characteristics (ROC) curve analysis was used to explore sensitivity and specificity for max and evaluated the optimal cutoff values for SUVmax in tests of significance were two-sided; $\mathrm{P}<0.05$ was considered significant. 
Current Trends in Clinical \& Medical Imaging

\begin{tabular}{|c|c|c|c|}
\hline \multirow{3}{*}{ TNM overall stage } & I & $2(5 \%)$ & $19(6.0 \%)$ \\
\cline { 2 - 4 } & II & $3(7.5 \%)$ & $29(9.1 \%)$ \\
\cline { 2 - 4 } & III & $14(35 \%)$ & $97(30.4 \%)$ \\
\cline { 2 - 4 } & IV & $21(52.5 \%)$ & $174(54.5 \%)$ \\
\hline
\end{tabular}

The characteristics and SUVmax of the 40 SCLC cases and 319 NSCLC cases are summarized in Table 1. Male were more frequent than female in both SCLC and NSCLC. The ratio male / female were much more in SCLC compare to that in NSCLC $(9 / 1$ vs $2.2 / 1$, respectively, $\mathrm{p}=0.006$ ). Tumor size $>5 \mathrm{~cm}$ in diameter were more frequent in SCLC $(62.5 \%, 25 / 40)$ than that of NSCLC $(36.7 \%, 117 / 319),(p=0.006)$. The tumor is likely to locate more frequently in upper lobe than others. The other characteristics including age, sex, tumor location, TNM overal stage between two groups were not different. The average of primary tumor size of SCLC is significantly greater than that of NSCLC $(5.9 \pm 2.5 \mathrm{~cm}$ vs $4.9 \pm 2.4 \mathrm{~cm}, \mathrm{p}=0.002$ ), while average of primary tumor SUVmax of SCLC is significantly smaller than that of NSCLC $(8.09 \pm 3.99$ vs $10.96 \pm 5.42 \mathrm{~cm}, \mathrm{p}=0.001$ ), showed in the Figures $1 \& 2$ (Table 1 ).
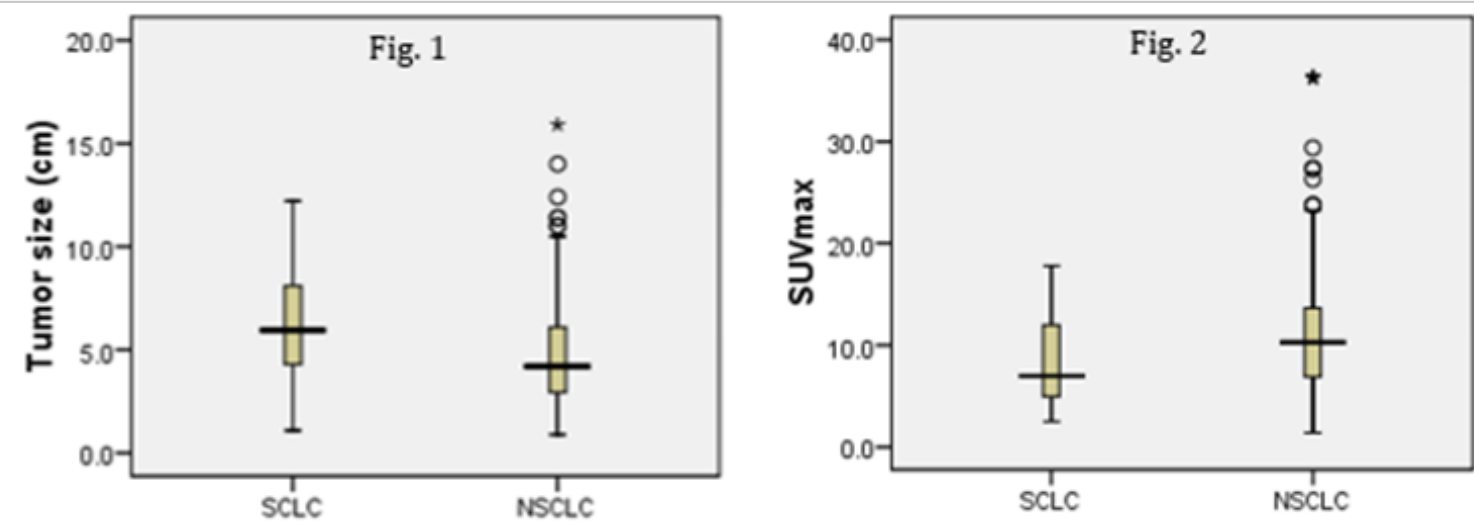

Figure 1 \& 2: Comparison of tumor size and SUVmax between SCLC and NSCLC.
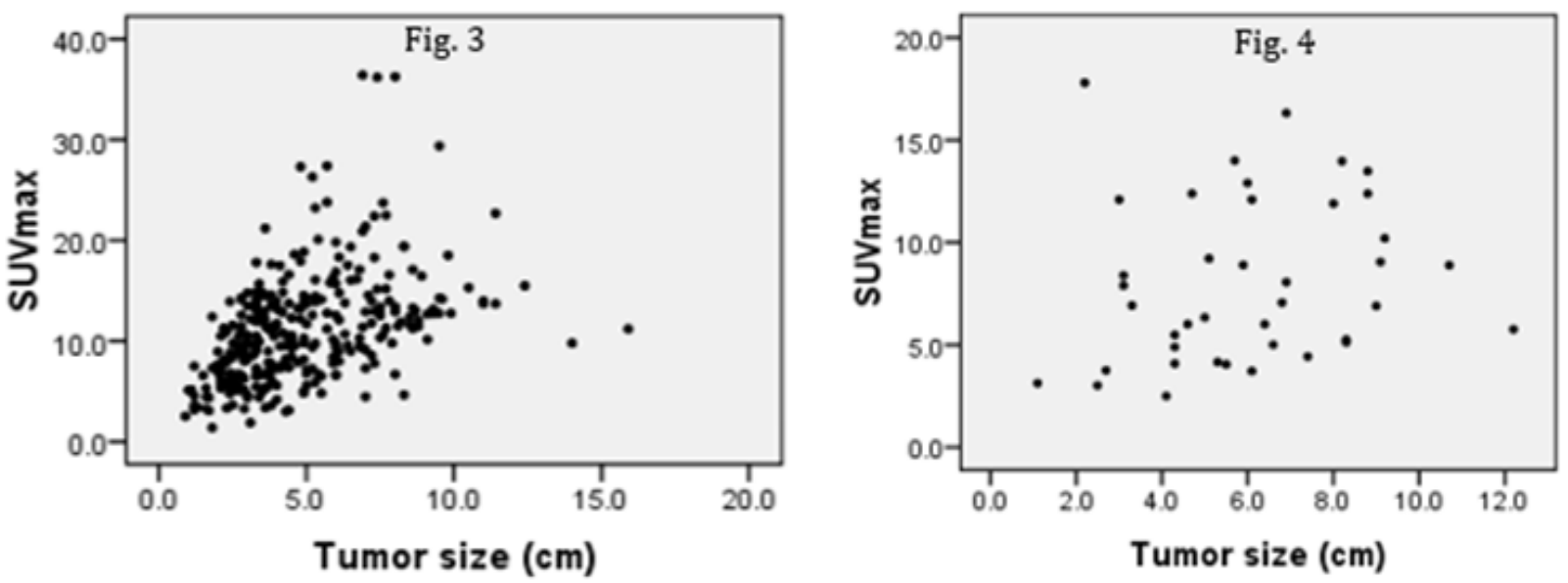

Figure 3 \& 4: Correlation between SUVmax and tumor size in NSCLC and SCLC .

There was a moderate correlation between SUVmax and tumor size $(\mathrm{r}=0.542, \mathrm{p}<0.001)$ in NSCLC but not significant in SCLC $(r=0.279, p=0.081)$ showed in Figures $3 \& 4$. There was a moderate between SUVmax and TNM overall stage in NSCLC $(r=0.513, p=0.01)$ but not significant in SCLC $(r=0.145, p=0.173)$. ROC area under the curve of primary tumor SUVmax for NSCLC involvement was 0.795 (95\% CI: 0.750-0.836), $\mathrm{p}<0.0001$. An optimal cut-off value was identified as 8.39 by ROC curve, the sensitivity and specificity were $94.7 \%$ and $60 \%$, respectively (Figure 5). Figures $6 \& 7$ shows the PET-CT images of patients with SCLC and NSCLC. 


\section{Current Trends in Clinical \& Medical Imaging}

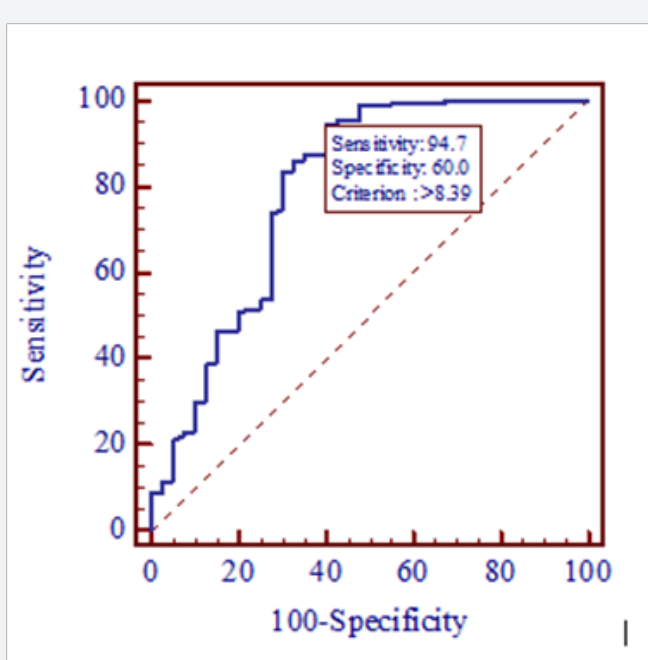

Figure 5: ROC curve of SUVmax to distingish primary tumor of NSCLC from SCLC. Overall accuracy was good, with area under ROC curve of $0.795(95 \% \mathrm{Cl}: 0.750-0.836), p<0.0001$.
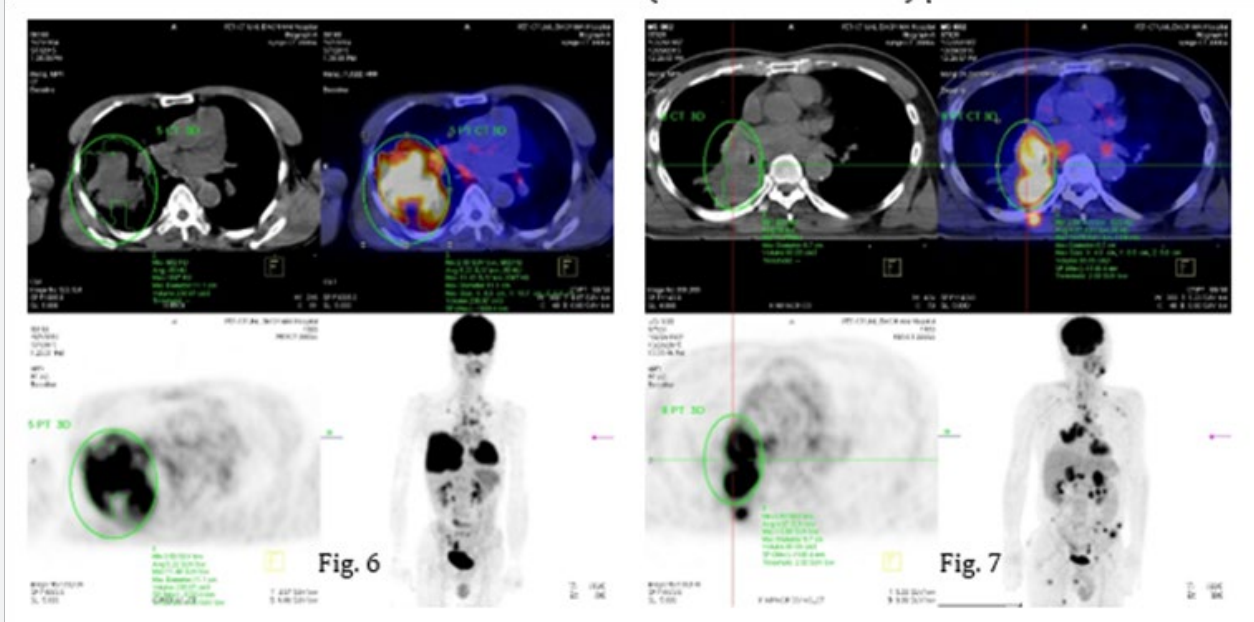

Figure 6 \& 7: PET-CT images of primary tumor. In case of SCLC (fig. 6), the tumor diameter is $11 \mathrm{~cm}$ and SUVmax is 11.4 . The other is a case of NSCLC (fig. 7) with the tumor diameter and SUVmax of $8.7 \mathrm{~cm}$ and 13 , respectively.

\section{Discussion}

Although CT or magnetic resonance imaging provides precise anatomical and morphological information, the role of FDGPET-CT has increased for diagnosis and staging of lung cancer. Recently, FDG uptake has been reported to be a prognostic factor in patients with lung cancer [15]. Patz et al. [16] demonstrated that patients with positive FDG-PET-CT results in treated lung cancer had a significantly worse prognosis than patients with negative results. Therefore, we examined whether SUVmax correlates with tumor size, TNM stage in patients with lung cancer.

For patients with lung carcinoma, the accurate determination of tumor type significantly influences treatment decision making. In general, SCLC is much more responsive to chemotherapy and consequently this comprises the mainstay of treatment. This is in contrast to NSCLC, which includes adenocarcinomas, squamous cell carcinomas, and large cell undifferentiated carcinomas of the lung.

Clinically, SCLC is more aggressive than non-small cell lung cancer (NSCLC), presenting with a rapid doubling time and higher propensity for widespread metastatic disease. Overall prognosis is severe: in fact, despite initial chemosensitivity, most patients with SCLC relapse and die from recurrent disease $[17,18]$. The impact of PET on stage classification of newly diagnosed SCLC has been investigated by several authors that reported how PET allowed a modification of stage and clinical management in $10-33 \%$ of cases. Fischer et al. reported that PET/CT could improve accuracy of SCLC staging with a higher sensitivity 


\section{Current Trends in Clinical \& Medical Imaging}

than conventional imaging ( $93 \%$ vs. $79 \%$, respectively) and equal specificity (100\%). In their population PET/CT findings determined a change of stage in 5 of 29 patients (17\%) [19].

In a population of 120 SCLC patients studied for staging by PET and conventional imaging, PET up-staged 10 patients and down-staged 3 patients [20]. Overall PET data resulted in a change of stage in $12 \%$ of patients. In a recent study Azad et al. found that PET altered stage classification in 12 of 46 (26\%) patients when compared with conventional imaging. In particular, among the 26 patients with limited disease on conventional imaging, 4/26 (15\%) were accurately upstaged to extended disease after PET while among the 20 patients with extended disease on conventional imaging, 8/20 (40\%) were downstaged to limited disease [21].

Only in one study PET did not alter stage classification in SCLC patients: infect Kut et al. [22], in their population, found that PET scan findings agreed with conventional imaging in the majority of cases [22]. In patients with NSCLC, Özgül et al. [23] examined whether SUVmax correlates with tumor size, lymph node and distant metastases in patients with NSCLC. Tumor size, but not lymph node or distant metastases, was related to the tumor SUVmax [23]. Doom et al. [24] also reported a strong significant association between tumor size and SUVmax in patients with NSCLC. Another study in patients with stage I NSCLC showed a significant association between the primary tumor, SUVmax and tumor size, with tumors $\leq 3 \mathrm{~cm}$ having a significantly lower SUV than tumors $>3 \mathrm{~cm}$ [25]. In addition, a retrospective analysis of 85 patients with solid pulmonary lesions found a positive correlation between the size of a malignant tumor and SUVmax [26]. A multivariate analysis demonstrated that the combination of high SUV and large lesion size identified a subgroup of patients with the worst prognosis and a median survival rate of less than 6 months [27].

\section{Conclusion}

The primary tumor SUVmax of NSCLC is significantly greater than that of SCLC. PET-CT could contribute to the differential diagnosis of NSCLC with SCLC with high sensitivity but low specificity. In addition, SCLC is more aggressive than NSCLC, presenting with a rapid doubling time and higher propensity for widespread metastatic disease.

\section{References}

1. Bray F, Ferlay J, Soerjomataram I, Siegel RL, Torre LA (2018) Global cancer statistics 2018: GLOBOCAN estimates of incidence and mortality worldwide for 36 cancers in 185 countries. CA Cancer J Clin 68(6): 394-424.

2. Sabour S (2018) Prediction of Post-operative Morbidity and Mortality in Patients with Lung Cancer: Methodological Issues. Lung 196(5): 499-500.

3. Stanzani F, Paisani Dde M, Oliveira A, Souza RC, Perfeito JA (2014) Morbidity, mortality, and categorization of the risk of perioperative complications in lung cancer patients. J Bras Pneumol 40(1): 21-29.
4. Verghese C, Redko C, Fink B (2018) Screening for Lung Cancer Has Limited Effectiveness Globally and Distracts From Much Needed Efforts to Reduce the Critical Worldwide Prevalence of Smoking and Related Morbidity and Mortality. J Glob Oncol (4): 1-7.

5. Clancy L (2014) Reducing lung cancer and other tobacco-related cancers in Europe: smoking cessation is the key. Oncologist 19(1): 1620.

6. Furrukh M (2013) Tobacco Smoking and Lung Cancer: Perceptionchanging facts. Sultan Qaboos Univ Med J 13(3): 345-358.

7. Takeuchi S, Khiewvan B, Fox PS, Swisher SG, Rohren EM (2014) Impact of initial PET/CT staging in terms of clinical stage, management plan, and prognosis in 592 patients with non-small-cell lung cancer. Eur J Nucl Med Mol Imaging 41(5): 906-914.

8. Ambrosini V, Nicolini S, Caroli P, Nanni C, Massaro A (2012) PET/CT imaging in different types of lung cancer: an overview. Eur J Radiol 81(5): 988-1001.

9. Sharma P, Singh H, Basu S, Kumar R (2013) Positron emission tomography-computed tomography in the management of lung cancer: An update. South Asian J Cancer 2(3): 171-178.

10. Divisi D, Barone M, Zaccagna G, Crisci R (2017) Fluorine-18 fluorodeoxyglucose positron emission tomography in the management of solitary pulmonary nodule: a review. Ann Med 49(7): 626-635.

11. Agarwal M, Brahmanday G, Bajaj SK, Ravikrishnan KP, Wong CY (2010) Revisiting the prognostic value of preoperative (18)F-fluoro2-deoxyglucose ((18)F-FDG) positron emission tomography (PET) in early-stage (I \& II) non-small cell lung cancers (NSCLC). Eur J Nucl Med Mol Imaging 37(4): 691-698.

12. de Cabanyes Candela S, Detterbeck FC (2010) A systematic review of restaging after induction therapy for stage IIIa lung cancer: prediction of pathologic stage. J Thorac Oncol 5(3): 389-398.

13. Fischer BM, Mortensen J, Langer SW, Loft A, Berthelsen AK (2006) $\mathrm{PET} / \mathrm{CT}$ imaging in response evaluation of patients with small cell lung cancer. Lung Cancer 54(1): 41-49.

14. Travis WD, Brambilla E, Nicholson AG, Yatabe Y, Austin JHM (2015) The 2015 World Health Organization Classification of Lung Tumors: Impact of Genetic, Clinical and Radiologic Advances Since the 2004 Classification. J Thorac Oncol 10(9): 1243-1260.

15. Pesch B, Kendzia B, Gustavsson P, Jockel KH, Johnen G (2012) Cigarette smoking and lung cancer--relative risk estimates for the major histological types from a pooled analysis of case-control studies. Int J Cancer 131(5): 1210-1219.

16. Patz EF Jr, Connolly J, Herndon J (2000) Prognostic value of thoracic FDG PET imaging after treatment for non-small cell lung cancer. AJR Am J Roentgenol 174(3): 769-774.

17. Akhtar-Danesh N, Finley C (2015) Temporal trends in the incidence and relative survival of non-small cell lung cancer in Canada: A populationbased study. Lung Cancer 90(1): 8-14.

18. Cheng S, Evans WK, Stys-Norman D, Shepherd FA (2007) Lung Cancer Disease Site Group of Cancer Care Ontario's Program in Evidencebased C Chemotherapy for relapsed small cell lung cancer: a systematic review and practice guideline. J Thorac Oncol 2(4): 348-354.

19. Fischer BM, Mortensen J, Langer SW, Loft A, Berthelsen AK (2007) A prospective study of PET/CT in initial staging of small-cell lung cancer: comparison with CT, bone scintigraphy and bone marrow analysis. Ann Oncol 18(2): 338-345.

20. Brink I, Schumacher T, Mix M, Ruhland S, Stoelben E (2004) Impact of [18F] FDG-PET on the primary staging of small-cell lung cancer. Eur J Nucl Med Mol Imaging 31(12): 1614-20. 


\section{Current Trends in Clinical \& Medical Imaging}

21. Azad A, Chionh F, Scott AM, Lee ST, Berlangieri SU (2010) High impact of 18 F-FDG-PET on management and prognostic stratification of newly diagnosed small cell lung cancer. Mol Imaging Biol 12(4): 443-451.

22. Kut V, Spies W, Spies S, Gooding W, Argiris A (2007) Staging and monitoring of small cell lung cancer using [18F]fluoro-2-deoxy-Dglucose-positron emission tomography (FDG-PET). Am J Clin Oncol $30(1): 45-50$.

23. Ozgul MA, Kirkil G, Seyhan EC, Cetinkaya E, Ozgul G (2013) The maximum standardized FDG uptake on PET-CT in patients with nonsmall cell lung cancer. Multidiscip Respir Med 8(1): 69.

24. Dooms C, van Baardwijk A, Verbeken E, van Suylen RJ, Stroobants S (2009) Association between 18F-fluoro-2-deoxy-D-glucose uptake values and tumor vitality: prognostic value of positron emission tomography in early-stage non-small cell lung cancer. J Thorac Oncol 4(7): 822-828.

25. Um SW, Kim H, Koh WJ, Suh GY, Chung MP (2009) Prognostic value of 18F-FDG uptake on positron emission tomography in patients with pathologic stage I non-small cell lung cancer. J Thorac Oncol 4(11): 1331-1336

26. Lu G, Wang Z, Zhu H, Chang L, Chen Y (2007) The advantage of PET and CT integration in examination of lung tumors. Int J Biomed Imaging 2007: 17131 .

27. Ahuja V, Coleman RE, Herndon J, Patz EF Jr (1998) The prognostic significance of fluorodeoxyglucose positron emission tomography imaging for patients with non-small cell lung carcinoma. Cancer 83(5): 918-924.

\section{Your next submission with Juniper Publishers} will reach you the below assets

- Quality Editorial service

- Swift Peer Review

- Reprints availability

- E-prints Service

- Manuscript Podcast for convenient understanding

- Global attainment for your research

- Manuscript accessibility in different formats

( Pdf, E-pub, Full Text, Audio)

- Unceasing customer service

Track the below URL for one-step submission https://juniperpublishers.com/online-submission.php 